\title{
МЕТОДИЧЕСКИЕ ПОЛОЖЕНИЯ ОБОСНОВАНИЯ РЕШЕНИЙ ПО РАЗВИТИЮ ЭНЕРГЕТИЧЕСКОГО КОМПЛЕКСА МЕГАПОЛИСА
}

\author{
(C) 2020 Бугаева Татьяна Михайловна \\ Высшая инженерно-экономическая школа \\ Санкт-Петербургский политехнический университет Петра Великого (СПбПУ), \\ Россия, Санкт-Петербург \\ E-mail: bugaeva@spbstu.ru
}

(C) 2020 Викторова Наталья Геннадьевна

доктор экономических наук, доцент, Высшая инженерно-экономическая школа Санкт-Петербургский политехнический университет Петра Великого (СПбПУ), Россия, Санкт-Петербург

E-mail:viknata@mail.ru

В статье рассматриваются основные методологические положения обоснования решений по развитию энергетического комплекса мегаполиса. Описана структура системы энергоснабжения мегаполиса, подчеркнуты ее особенности. Перечислены основные требования к разрабатываемому модельному обеспечению работ по планированию развития энергетического комплекса мегаполиса.

Ключевые слова: энергетический комплекс мегаполиса; планирование развития; обоснование решений; экономико-математическое моделирование.

Под энергетикой (энергетическим хозяйством) принято понимать совокупность процессов и установок по добыче, облагораживанию, переработке, хранению, производству, преобразованию, передаче, распределению и использованию в народном хозяйстве всех видов энергии и топлива [2].

Благодаря трудам Мелентьева Л.А., Руденко Ю.Н., Макарова А.А., Беляева Л.С., Воропая Н.И., Х Хабачева Л.Д. и др. была сформирована методология системных исследований в энергетике [13]. Согласно ключевым работам $[6,7,15,23]$ можно выделить три основных объекта системных исследований:

- энергетические технологии;

- энергетические системы;

- энергетические комплексы.

Рассмотрим эти понятия. Энергетические технологии - это процессы и установки преобразования и транспорта энергетической продукции. Энергетическая продукция представляет собой электрическую и тепловую (в виде пара и горячей воды) энергию. Энергетические системы (далее - ЭС) по производственному признаку подразделяются на системы электроснабжения, теплоснабжения и системы топливообеспечения. Энергетический комплекс (далее ЭК) - взаимосвязь энергетических систем. Представление

энергетического комплекса в виде иерархически связанных систем элекроснабжения, теплоснабжения и топливообеспечения, системы конечного потребления энергии в системном аспекте получили название общеэнергетической системы $[6,15]$.

Общенергетические системы можно рассматривать на различных территориальных уровнях. Возможно наличие единой энергетической системы страны или группы стран. В тоже время общеэнергетическую систему страны можно рассмотреть, как совокупность территориальных энергетических систем. Лисин Е.М. для обобщения территориального уровня исследования систем энергетики вводит понятие территориально-административного образования (далее ТАО) - «территориальная единица или их совокупность, характеризующаяся территориальными связями и хозяйственным единством, которую можно выделить в границах государственных и муниципальных задач управления, решение которых направлено на обеспечение жизнедеятельности местного населения» [13, стр. 33].

Одним из уровней ТАО - является город. «Город - специфическая пространственная среда, которая формируется в процессе развития общества и становится материальной оболочкой 
множества важнейших сторон и проявлений общественной жизни» [18, с. 15].

С точки зрения производственной структуры энергетический комплекс города представляет собой совокупность энергетических систем, входящих в структуру системы энергоснабжения города (электро- и теплоснабжение).

В системе энергоснабжения города можно выделить три основных элемента - это подсистема производства или преобразования ресурсов в энергетическую продукцию; подсистема транспорта энергетической продукции; подсистема потребления энергетической продукции (рис.1).

Производство энергетической продукции. В качестве энергетических ресурсов рассматриваются невозобновляемые и возобновляемые первичные источники энергии. К невозобновляемым ресурсам относится топливо органического и неорганического происхождения. В крупных мегаполисах в качестве основного топлива для электростанций, расположенных на территории города, используется природный газ. К возобновляемым источникам энергии относятся энергия ветра, солнечная энергия, отходы, энергия, получаемая из биотоплива и др. Однако эти источники энергии не получили пока существенного распространения в мегаполисах России.
Технологии преобразования ресурсов в энергетическую продукцию - это любые технологии, способные преобразовать энергетические ресурсы в полезные тепло, горячую воду или электричество. К ним относятся котлоагрегаты, двигатели, турбины, солнечные фотоэлектрические и тепловые технологии, тепловые насосы и т.д.

Подсистема транспорта энергетической продукции включает транспорт электрической энергии по линиям электропередач, которые отличаются протяженностью, передаваемой мощностью и напряжением электрического тока, и транспорт тепловой энергии, который осуществляется посредством магистральных и распределительных тепловых сетей. Схема тепловой сети определяется размещением источников тепла по отношению к потребителям, видом теплоносителя, характером тепловых нагрузок и их расчетной величиной. Выбор конфигурации сети является важной задачей при проектировании систем энергоснабжения.

K потребителям системы энергоснабжения относятся здания различного назначения, отрасли промышленности, которые классифицируются по виду энергетических услуг (электричество, пар, горячая вода), географическому положению, уровням потребления.

В территориальном отношении система энергоснабжения города обладает тесными и

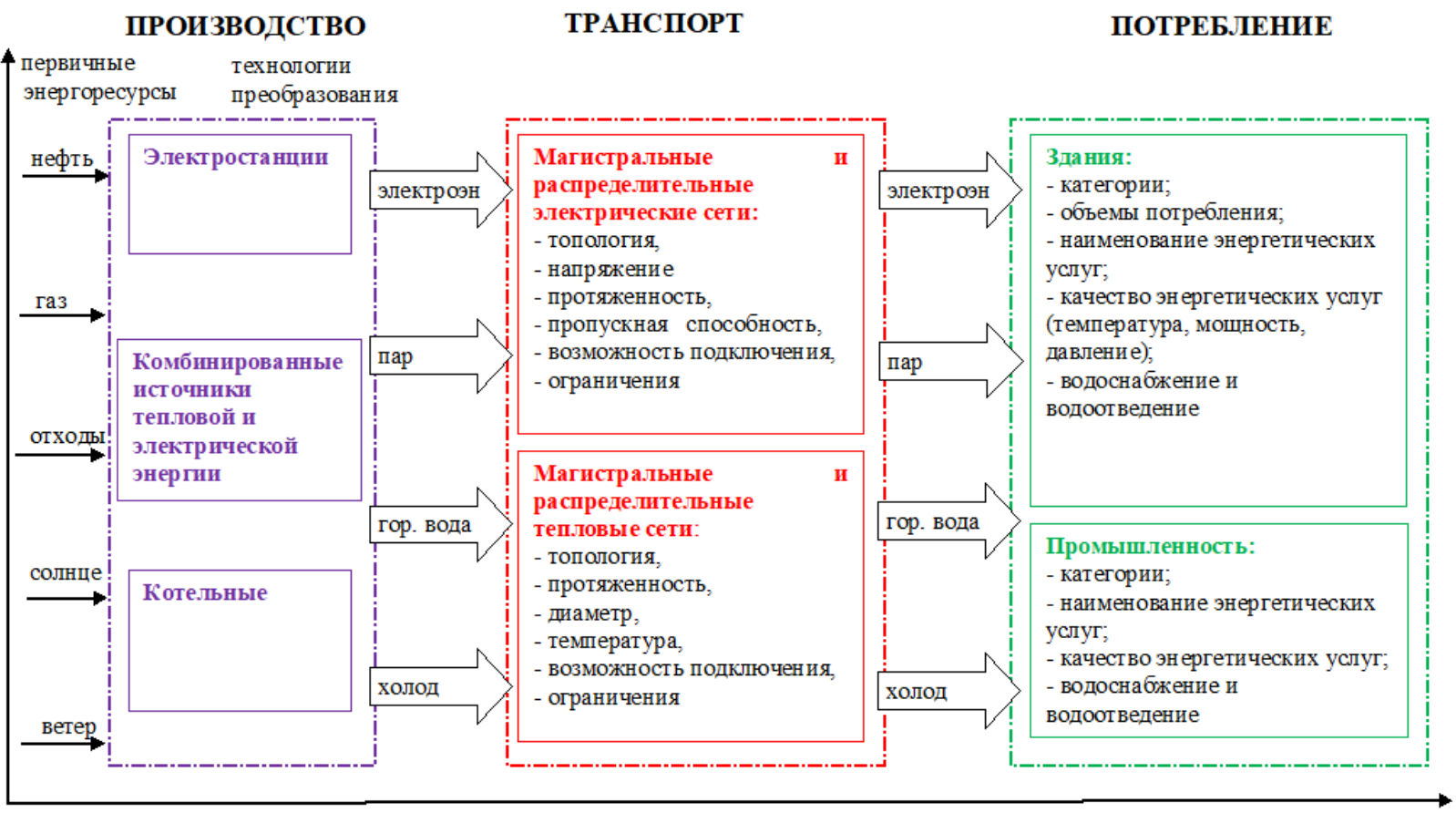

Рисунок 1. Система энергоснабжения города 
многообразными горизонтальными связями с другими городскими системами, например, системой топливоснабжения (газоснабжения), водоснабжения, строительства, землепользования, транспорта, связи (рис.2).

Градостроительным кодексом Российской Федерации (далее - РФ) установлены следующие виды городов [1]:

- сверхкрупные города (численность населения свыше 3 млн. чел.);

- крупнейшие города (от 1 до 3 млн. чел.);

- крупные города (от 250 тыс. до 1 млн. чел.);

- большие города (от 100 до 250 тыс. чел.);

- средние города (от 50 до 100 тыс. чел.);

- малые города (до 50 тыс. чел.).

В научной литературе встречаются исследования, в которых крупнейшие города РФ, такие как Москва, Санкт-Петербург, Екатеринбург называют «мегаполисами» [24]. В толковом словаре Б.А.Райзберга: «Мегаполис, мегалополис (от греч. род. п.- megas, megalus - большой и polis - город) - самая крупная форма городско- го расселения, образующаяся в результате интеграции главного города с окружающими его поселениями, агломерациями» [17]. С точки зрения численности городского населения существуют разные трактовки понятия «мегаполис», однако автор придерживается мнения, согласно которому к мегаполисам относятся города с численностью населения более 3 млн. чел.

В иерархическом построении систем энергоснабжения мегаполиса можно выделить следующие уровни: 1) система энергоснабжения одного здания; 2) система энергоснабжения района города (нескольких близкорасположенных зданий); 3) система энергоснабжения города.

Системы энергоснабжения мегаполисов России характеризуются [3]:

- единством технологических процессов, режимов и неразрывностью процесса производства, передачи и распределения энергии на предприятиях, входящих в систему энергообеспечения города;

- большим числом собственников и хозяй-

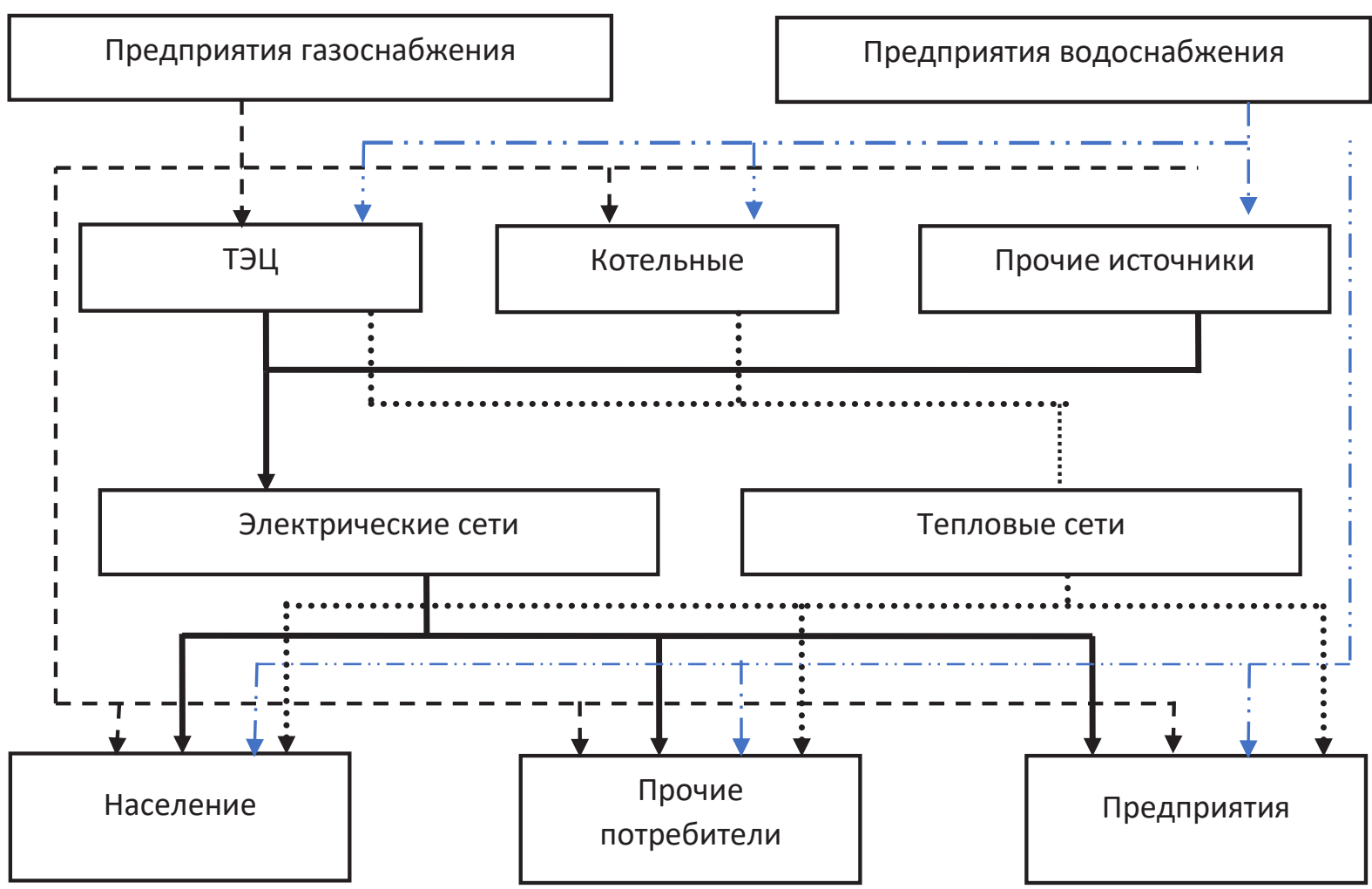


ствующих субъектов и отсутствием согласованного планирования перспективного развития энергоснабжения города, включая вводы генерирующих мощностей, реконструкцию систем и модернизацию оборудования, недостаточно эффективным использованием топливноэнергетических ресурсов (ТЭР);

- повышенными требованиями к надежности систем энергоснабжения города, обусловленными большим числом ответственных потребителей, не допускающих нарушений в подаче тепла, электроэнергии и газа, практически монотопливным балансом и жесткими требованиями к надежности газоснабжения;

- высокой потребностью в инвестиционных ресурсах для реконструкции и модернизации, недостатком свободных территорий и крайней дороговизной площадок для строительства энергообъектов, прежде всего магистральных транспортных сетей;

- особенностями энергоснабжения крупнейших российских городов, связанными с его теплофикационной основой, высочайшим уровнем централизации и концентрации производства тепла;

- наличием ограничений на получение дополнительных ресурсов природного газа в связи с общими ресурсными ценовыми ограничениями и необходимостью сооружения новых магистральных газопроводов, что может сдерживать строительство новых объектов генерации.

Также одним из важных факторов существования и развития системы энергоснабжения мегаполиса является уникальность ее пространственной структуры [12]. Расположение объектов инженерной инфраструктуры и потребителей на территории оказывают влияние на многие процессы жизнедеятельности города.

Система энергоснабжения мегаполиса является многоуровневым, многофункциональным территориальным и производственным комплексом, поэтому модели и механизмы управления его развитием должны адекватно учитывать сложность и структурированность, технико-экономические взаимосвязи и иметь целью повышение социальной эффективности, экологической безопасности, качества энергетической продукции и энергетической безопасности города.

Разработка методов и организационноэкономических механизмов управления развитием энергетического комплекса мегаполиса связана с:

- использованием принципов исследования больших иерархических систем, положений теории оптимальных решений, методов математического моделирования;

- согласования разрабатываемых методов и механизмов управления с действующей производственно-организационной структурой электроэнергетики, составом и целевыми установками хозяйствующих субъектов отрасли, и экономическими отношениями между ними, условиями получения финансовых и энергетических ресурсов для развития [18].

При решении задачи оптимального управления развитием энергетического комплекса мегаполиса необходимо:

- проводить экономическую оптимизацию совместного функционирования энергетических объектов (источников генерации, электрических и тепловых сетей) в составе системы энергоснабжения мегаполиса в различных временных разрезах;

- учитывать существующую пространственную структуру города и тенденции ее развития, технологические и экономические связи системы энергоснабжения мегаполиса с другими территориальными производственными системами;

- учитывать сложность количественного описания учитываемых в модели финансовых и ресурсных ограничений;

- учитывать условия неопределенности и многокритериальности.

Основные трудности в реализации системного планирования заключаются в необходимости использования единого методического и модельного инструментария, в отсутствии достаточного информационного обеспечения. Необходимы комплексные многовариантные оптимизационные исследования, циклы межуровневых итерационных согласований по прямых и обратным связям, что требует выстраивания последовательной процедуры действий, управление и организацию работ из специализированного центра ответственности.

Для изучения и оптимизации энергетических систем применяется экономико-математическое моделирование. Оптимизационные задачи энергетики многоцелевые, нелинейные, динамические, дискретные, имеют большие размеры и недостаточную (с формальной точки зрения) информационную базу [6]. Имитацион- 
ное моделирование и оптимизация энергетических систем городов с различным уровнем детализации, представляют интерес для многих исследователей [26]. К настоящему времени разработано достаточно большое число математических моделей и программ для решения различных задач стратегического планирования и комплексного энергетического моделирования $[16,25]$. Многообразие моделей является очевидным подтверждением того, что использование прогнозирования и планирования - неотъемлемая практика практически во всех экономически развитых странах.

Энергетический комплекс мегаполиса обладает характеристиками, позволяющими выделить его как самостоятельных объект оптимизационных исследований. Основным методическим принципом исследования и оптимизации систем энергоснабжения мегаполиса должен стать комплексный подход, который за- ключается в совместном рассмотрении и поиске скоординированных решений по развитию энергетических систем мегаполиса с учетом пространственных ограничений города, неопределенности условий развития и множественности интересов.

Необходима разработка методов и моделей имитационных и оптимизационных, которые смогут стать основой системы поддержки принятия решений по развития системы энергоснабжения мегаполиса. Создаваемая система должна включать:

1. Базу данных, в которой будет аккумулироваться и обрабатываться необходимая информация.

2. Блок прогнозирования уровней и режимов потребления энергетических услуг.

3. Блок обоснования рациональной структуры и размещения объектов энергетического комплекса.

\section{Библиографический список}

1. Градостроительный кодекс РФ: от 29.12.2004 № 190-Ф3 (ред. от 31.04.2020). URL: http: //www.consultant.ru/ document/cons_doc_LAW_51040/ (дата обращения: 2.09.2020).

2. Ащеулова И.Е. Управление техническим развитием компаний: автореферат дис. ... канд. экон. наук: 08.00.05 - Москва, 2011.- 23 с.

3. Бугаева Т.М., Хабачев Л.Д. Комплексный подход к планированию развития энергетического комплекса мегаполиса (на примере Санкт-Петербурга) [An integrated approach to planning the development of the energy complex of a megalopolis (on the example of Saint Petersburg)] // Научно-технические ведомости СанктПетербургского государственного политехнического университета. Экономические науки. 2013. № 2 (168).

4. Галиева Д.А., Иванова Е.Г., Конников Е.А., Конникова О.А. Принципы формирования эффективных проектов в области повышения энергоэффективности деятельности предприятия // Экономические науки. 2020. № 188. С. 37-42.

5. Лисин E.M. Методологические аспекты обеспечения энергетической безопасности на территориальном уровне в условиях либерализации и глобализации энергетики.-М.: НИУ «МЭИ», 2018. 232 с.

6. Воропай, Н.И. Системные исследования в энергетике: Ретроспектива научных направлений СЭИ-ИСЭМ / Н.И. Воропай, Н. В.Абасов, А.С.Апарцин, Л. С. Беляев, Т. В.Бережных, О.Н. Войтов, Ю.А. Гришин - Новосибирск: Издательство Института систем энергетики им. Л.А. Мелентьева СО РАН, 2010.-686 с.

7. Воропай, Н.И., Подковальников, С.В., Труфанов, В.В., Беляев, Л.С., Гальперова, Е.В., Домышев, А.В., Кононов, Ю.Д. Обоснование развития электроэнергетических систем: методология, модели, методы, их использование. Новосибирск: Наука, 2015.-448 с.

8. Кичигин О.Э., Родионов Д.Г. Институциональный аспект формирования стратегических ориентиров государственной энергетической политики на региональном уровне при реализации стратегии национальной экономической безопасности // Экономика и предпринимательство. 2017. № 10-2 (87). С. 394-399.

9. Конников Е.А., Бразовская В.В., Куропятник А.С. Прогнозирование производства первичных энергоресурсов // В сборнике: Неделя науки СПбПУ. Материалы научной конференции с международным участием. Институт промышленного менеджмента, экономики и торговли. В 3-х частях. 2019. С. 706-708.

10. Конников E.A. Инвестиционная привлекательность энергетических проектов макроуровня на примере концепции энергетического поворота Германии // В сборнике: Эффективная энергетика-2015. Материалы научно-практической конференции с международным участием. 2015. С. 56-66.

11. Конников Е.А., Мансуров Р. Д., Михеев П. С., Ниемб Б. С. Источники медиирования инвестиций в возобновляемые источники энергии // Экономические науки. 2020. № 185. С. 132-139. 
12. Косяков С. В. Пространственное моделирование энергоснабжения городских территорий // Тез. докл. межд. научн.- техн. конф. «Состояние и перспективы развития электротехнологии» (XI Бернадосовские чтения).- Иваново: Иван. гос. энерг. ун-т, 2003.- Т. 1.- С. 80.

13. Лисин E.M. Методологические аспекты обеспечения энергетической безопасности на территориальном уровне в условиях либерализации и глобализации энергетики.-М.: НИУ «МЭИ», 2018. 232 с.

14. Макаров, А. А. Системные исследования развития энергетики / А. А. Макаров.- Москва: МЭИ, $2015 .-280$ с.

15. Мелентьев, Л. А. Методология системных исследований в энергетике. Избранные труды. / Л. А. Мелентьев.Москва: Издательство Наука, 1995.- 289 с.

16. Никитин С. Н., Войтехович И.В., Филютич И. С. Компьютерные модели для прогнозирования, стратегического и энергетического планирования //Научные труды: Институт народнохозяйственного прогнозирования РАН.-2012.- № . 10.

17. Райзберг Б.А., Лозовский Л. Ш., Стародубцева Е. Б. Современный экономический словарь. - 5-е изд., перераб. и доп.- М.: ИНФРА-М, 2006. - 495 с. - (Библиотека словарей «ИНФРА-М»).

18. Ресин В.И., Попков Ю.С. Развитие больших городов в условиях переходной экономики (системный подход). Изд. 2-е - М.: Книжный дом «ЛИБРОКОМ», 2013.- 328 с.

19. Родионов Д.Г., Баранова И. В., Насрутдинов М.Н. Идентификация ключевых медиаторов развития социального потенциала региона // Российский экономический интернет-журнал. 2019. № 3. С. 69.

20. Родионов Д.Г., Баранова И. В., Насрутдинов М. Н. Формирование модели интерферирования показателей социального потенциала региона // Российский экономический интернет-журнал. 2019. № 4. С. 119.

21. Родионов Д.Г., Рудская И. А. Региональные инновационные системы, их роль и место в формах инновационной кооперации // В сборнике: Финансовые решения XXI века: теория и практика. Сборник научных трудов 16-й Международной научно-практической конференции. Санкт-Петербургский политехнический университет Петра Великого; Ответственные за выпуск Д. Г. Родионов, Т. Ю. Кудрявцева, Ю. Ю. Купоров. 2015. С. 157-164.

22. Хабачев Л.Д. Методы и механизмы управления развитием электроэнергетических систем: автореф. дис.... д-р. экон. наук: 08.00.05.- СПб., 1997.

23. Хабачев Л.Д. Технико-экономическое планирование развития электроэнергетических систем. СПб.: Издво Политехн. ун-та, 2014. 176 с.

24. Чекалин В.С., Любарская М. А., Ермакова М. Ю. Энергетический комплекс крупного города: проблемы и пути развития // Известия Санкт-Петербургского государственного экономического университета. 2020. № 4 (124).

25. Andrea Herbst, Felipe Toro, Felix Reitze, and Eberhard Jochem. 2012. Introduction to Energy Systems Modelling. Swiss J. Econ. Stat. 148, 2 (2012), 111-135. DOI: https://doi.org/10.1007/bf03399363

26. James Keirstead, Mark Jennings, and Aruna Sivakumar. 2012. A review of urban energy system models: Approaches, challenges and opportunities. Renew. Sustain. Energy Rev. 16, 6 (2012), 3847-3866. DOI: https://doi.org/10.1016/j. rser.2012.02.047 